\title{
(t)
}

\section{A FORMAÇÃO PROFISSIONAL E O FORTALECIMENTO DO SERVIÇO SOCIAL COMO ÁREA DE CONHECIMENTO: ESTRATÉGIAS E DESAFIOS DA ABEPSS NO BIÊNIO 2007-2008}

Professional formation and strengthening of Social Work as a field of knowledge - strategies and challenges for Abepss in the biennium 2007 and 2008

\section{Marina Maciel Abreu²}

\section{INTRODUÇÃO}

É motivo de grande alegria e profunda emoção participar do número especial da Revista Temporalis, alusivo aos 65 anos da Associação Brasileira de Ensino e Pesquisa em Serviços Social (Abepss), e contribuir, com base no debate e trabalho coletivo desenvolvidos na gestão 2007-2008, no esforço a que se propõe essa publicação de recuperação histórica do protagonismo da entidade, desde a sua reestruturação em 1998. Tem-se que o ano de 1998 marca o redimensionamento das funções precípuas da entidade "[...] como associação de natureza acadêmico-científica na área do Serviço Social" (ABEPSS, 2008a), reafirmando-se como uma referência fundamental do desenvolvimento do Serviço Social brasileiro, em sua vinculação às lutas e resistência da classe trabalhadora orientadas pelo ideário

\footnotetext{
'Texto elaborado com base em documentos do Dossiê Abepss Gestão (2007-2008), registros do debate e manifestações da diretoria da entidade no referido biênio .

${ }^{2}$ Assistente Social, Doutora em Serviço Social, Professora do Programa de Pós-Graduação e Políticas Públicas da UFMA, Pesquisadora Bolsista do Conselho Nacional de Desenvolvimento Científico e Tecnológico (CNPq), Presidente da Abepss, gestão 2007-2008.
} 
da emancipação humana que passa pelas conquistas no campo dos direitos, mas implica uma luta permanente contra as forças do retrocesso.

Com este novo perfil, a entidade dá um salto qualitativo na adequação de sua estrutura e dinâmica de funcionamento aos avanços acadêmicos, científicos e profissionais e aos processos democráticos no âmbito do Serviço Social impulsionados a partir de 1979, em que se destacam: o início da pós-graduação desde 1972 e a constituição e hegemonia do hoje denominado projeto ético-político profissional, na direção das lutas e organização dos trabalhadores em ascensão naquele contexto. Hoje, esses processos estão profundamente tensionados pelas estratégias neoliberais de reestruturação do capital em crise marcados principalmente pela flexibilização das relações de trabalho, fragmentação da classe e negação de direitos conquistados historicamente e ampliados com a Constituição Federal de 1988; e apontam um refluxo, sobretudo do núcleo dominante do movimento sindical, em relação às concepções socialistas e anti-capitalistas, presentes nos anos 1980, "[...] em nome de uma acomodação dentro da ordem" (ANTUNES, 1999, p. 241).

No biênio 2007-2008, a entidade sediada na Universidade Federal do Maranhão (UFMA) - na qual estava vinculado o núcleo central acadêmico-político-administrativo da Executiva Nacional ${ }^{3}$ - privile-

\footnotetext{
${ }^{3}$ Composição da Diretoria da Abepss no biênio 2007-2008: Marina Maciel Abreu (Presidente/UFMA), Maria Eunice Pereira Damasceno Ferreira (Secretária/UFMA); Raimunda Nonata do Nascimento Santana (Tesoureira/UFMA), Josefa Batista Lopes (Coordenadora Nacional de Pós-Graduação/UFMA), Ângela Santana do Amaral (Coordenadora Nacional de Graduação/UFPE), Marieta Koike dos Santos (Coordenadora de Relações Internacionais/UFPE), Franci Gomes Cardoso (Suplente/UFMA), Lourdes de Maria Leitão Nunes Rocha (Suplente/UFMA); as seis Vices-Presidentes: Maria do Rosário de Fátima Silva/Regional Norte/UFPI, Sâmya Rodrigues Ramos/Regional Nordeste/Uern; Izabel Cristina Lira/Regional Centro-Oeste/UFMT; Cleusa Santos/Regional Leste/UFRJ; Elisa Maria Andrade Brisola/ Regional Sul II/Unitau; Maria Izabel Scheidt Pires/Regional SUL I/PUCPR; e representação estudantil: Jorge Og de Vasconcelos Junior (Representante Estudantil Nacional de Graduação/UFF) e Amanda Valéria de Sousa Lima (Suplente/UFPA), Tássia Rejane Monte dos Santos (Representante Estudantil Nacional de Pós-Graduação/UFRN) e Daniela Neves (suplente/UFRJ). As diretorias regionais, além das Vices-Presidentes já citadas, estão organizadas a partir de: Regional Norte: Lília Penha Viana Silva (Coordenadora Regional de Graduação/UFMA); Carlos Alberto Batista Maciel (Coordenador Regional de Pós-Graduação/UFPA); Nazaré Mendonça das Neves (Representante de Supervisora); Luciana Azevedo (Representante estudantil/UFMA). Regional Nordeste: Telma Gurgel da Silva (Coordenadora Regional de Graduação/Uern); Reivan Marinho de Souza Carneiro (Coordenadora Regional de Pós-Graduação/Ufal); Fábio dos Santos (Representante Estudantil de Graduação/UFPB); Romênia Moura Sousa (Representante Estudantil de Graduação suplente/Uern); Mara Betânia Sales (Representante Estudantil de Pós-Graduação/UFPE); Francisco Henrique da Costa Rozendo (Representante estudantil de Pós-Graduação suplente/Uern); Regional Centro-Oeste: Jaime Hillesheim (Coordena-
} 
giou, dentre os desdobramentos das diretrizes gerais ${ }^{4}$, as seguintes estratégias que passam a compor os eixos desta reflexão: 0 fortalecimento da unidade graduação e pós-graduação, principal fundamento do desenvolvimento acadêmico da área do Serviço Social e da atuação da Abepss; a reestruturação da Revista Temporalis como revista brasileira da Abepss na perspectiva do seu enquadramento nos padrões nacionais e internacionais de indexação bibliográfica e nas atuais exigências do Qualis da Capes; avanço e ampliação das articulações políticas com entidades profissionais e estudantis da área do Serviço Social, e outras entidades sindicais e movimentos sociais a partir de um conjunto de ações que privilegia as questões da formação e do exercício profissional; e a revisão dos estatutos da Abepss, considerando a necessidade de urgente

dor Regional de Graduação/UFMT); Regina Sueli de Sousa (Coordenadora Regional Pós-Graduação/ UCG); Greyce Kelle de Oliveira Neves (Representante Estudantil Regional de Graduação/UFMT); Neimy Batista da Silva (Representante Estudantil Regional de Pós-Graduação/UnB); Regional Leste: Leila Escorsin Netto (Coordenadora Regional de Graduação/UFRJ); Ana Maria de Vasconcelos (Coordenadora Regional de Pós-Graduação/Uerj); Cristiano Costa de Carvalho (Representante Estudantil regional da Graduação/PUCMG); Wallace Gomes (Representante Estudantil Regional de Graduação - suplente/Emescam/ES); Regional Sul I: Maria Tereza dos Santos ( Coordenadora Regional de Graduação/UFSC); Ana Lúcia Suárez Maciel (Coordenadora Regional de Pós-Graduação/PUCRS); Kizzy Vecchio (Representante Estudantil Regional de Graduação/PUCRS); Valter Martins (Representante Estudantil Regional de Pós-Graduação/UFSC); Regional Sul II: Maria Liduína Oliveira e Silva (Coordenadora Regional de Graduação/Fama); Padre Mário José Filho (Coordenador Regional de Pós-Graduação/Unesp). Integram o Conselho Fiscal: Ana Maria B. Cartaxo/UFCS; Maria da Conceição Pio/Uece; Mariângela Belfiore Wanderley/PUCSP.

${ }^{4}$ A atuação da Abepss orientou-se, no biênio 2007-2008, nas seguintes diretrizes gerais: (a) defesa das diretrizes curriculares para o curso de Serviço Social, aprovadas em 1996 no âmbito da Abepss e em 2001 pelo Conselho Nacional de Educação (CNE), considerando a necessidade de contínuo avanço de sua construção e aprofundamento como processo histórico em permanente elaboração a partir das lutas de resistência e defesa de uma educação emancipatória, no confronto com as estratégias de flexibilização da educação e da pesquisa para o mercado impostas pela atual (contra) reforma da educação superior no país; (b) consolidação da articulação dos programas de pós-graduação de forma autônoma em relação às agências de fomento, mas com a clareza da importância da interlocução com as mesmas a partir de diretrizes político-pedagógicas e de linhas estratégicas de atuação acadêmica com a incorporação de necessidades do ensino de graduação em Serviço Social; (c) fortalecimento do Serviço Social como área de conhecimento, em que se destacam a necessidade de revisão das subáreas de conhecimentos junto aos órgãos de fomento $\mathrm{CNPq}$, Coordenação de Aperfeiçoamento de Pessoal de Nível Superior (Capes) e Financiadora de Estudos e Projetos (Finep), a formação de Grupos Temáticos de Pesquisa (GTP) no âmbito da Abepss e o fortalecimento da Revista Temporalis como Revista Brasileira da Abepss, com a perspectiva de expansão internacional e enquadramento nos padrões nacionais e internacionais de indexação bibliográfica e nas atuais exigências do Qualis da Capes; (d) criação de condições físico-estruturais básicas, necessárias ao exercício das funções acadêmico-científicas, políticas e administrativas da entidade e à garantia de continuidade dos trabalhos nas passagens de gestão, particularmente as atividades relacionadas à Revista Temporalis e à preservação da memória da entidade; (e) avanço e ampliação das articulações políticas com entidades profissionais da área do Serviço Social, e outras entidades sindicais e movimentos sociais como a partir de um conjunto de ações que privilegia as questões da formação e do exercício profissional (ABEPSS, 2007). 
adequação da estrutura e funcionamento da referida associação às demandas e desafios do Serviço Social - principalmente em relação à criação de novos órgãos de apoio ao seu desempenho num contexto contraditório, em que se confrontam as estratégias da atual (Contra) Reforma do Ensino Superior, centradas na flexibilização da educação e da pesquisa para o mercado, e as lutas de resistência e defesa do projeto profissional orientado pelo ideário da emancipação humana.

\section{O FORTALECIMENTO DA UNIDADE GRADUAÇÃO/PÓS-GRADUAÇÃO}

Esta estratégia se respalda no investimento histórico da Abepss na busca da unidade graduação e pós-graduação, tendo a produção do conhecimento apoiada na pesquisa como eixos articuladores do desenvolvimento acadêmico-teórico do Serviço Social e como um princípio básico em sua trajetória enquanto associação acadêmico-científica.

A busca da unidade entre os dois níveis da formação profissional é uma marca substantiva do trabalho da entidade, vinculada à visão de totalidade da educação crítica e emancipatória que se confronta com a tendência fragmentária e dualista da atual política de Ensino Superior no país, voltada para uma formação por competência, isto é pragmática, flexível e instrumental. As conquistas relacionadas à unidade graduação e pós-graduação ainda são recentes no âmbito da Abepss, ao se considerar o fato de que as unidades de formação acadêmica no nível da graduação constituem a base histórica da entidade desde a sua origem, enquanto a pós-graduação stricto sensu em seu desenvolvimento inicial concretizou-se com certo distanciamento em relação à articulação da então Abess, embora tenha sido esta a grande propulsora da pós-graduação com a realização das primeiras experiências lato sensu nos anos 1960. Vale lembrar que esse distanciamento foi responsável por um movimento na década de 1990 para a criação de uma entidade específica da pós-graduação, que provocou grande debate e resistência de grupos que viam a importância do avanço acadêmico do Serviço Social com o necessário fortalecimento da unidade graduação e pós-graduação, culminando com o reforço à reestruturação da 
Abess em Abepss para incorporar em sua estrutura a particularidade acadêmico-política da pós-graduação e, com ela, a pesquisa para seu fortalecimento e, ao mesmo tempo, uma estratégia de aprofundamento da interlocução com os órgãos de fomento, na medida em que estes têm a pós-graduação como a principal referência da pesquisa em todas as áreas do conhecimento.

Com este entendimento, a diretoria da Abepss na gestão 20072008 dá continuidade ao processo de criação e consolidação de um espaço específico para o debate e articulação nacional dos programas de pós-graduação, na unidade com o ensino de graduação, assim como dos pesquisadores, docentes e estudantes da área do Serviço Social, considerando principalmente a necessidade de adensar a discussão sobre o perfil da pós-graduação em Serviço Social, face aos padrões de excelência e às exigências da Capes para a área das Ciências Sociais Aplicadas, na qual se inscreve o Serviço Social, em que a pesquisa e a produção intelectual têm centralidade (ABEPSS, 2008b). Neste aspecto, em particular, inscrevem-se como mecanismos mobilizadores grandes eventos nacionais: o Enpess já consolidado como espaço de incentivo, divulgação e socialização do conhecimento produzido e de intercâmbio e articulação entre pesquisadores da área e áreas afins; a Oficina Nacional de Formação Profissional - estratégia que está na origem da Abepss (a entidade, desde 1996, vem utilizando a metodologia das oficinas no processo de discussão dos temas de interesse desse nível de formação acadêmica e profissional); e o Seminário Nacional de Pós-Graduação, inaugurado na gestão anterior (2005-2006) e orientado para responder a demandas colocadas pela reestruturação da Política Nacional de Educação que impõem para a Abepss, como uma exigência estratégica de sua atuação, o aprofundamento do debate sobre os impactos das reformas propostas, nos dois níveis de formação e na produção do conhecimento Serviço Social.

Em 2008, justificou-se a realização conjunta do II Seminário Nacional de Pós-Graduação e a Oficina Nacional de Graduação com a mesma temática, possibilitando a professores, estudantes e pesquisadores participarem de forma unificada do debate e análise de questões que interessam aos dois níveis de formação acadêmica e profissional. 
Reafirmou-se, portanto, a estratégia da Oficina Nacional da Graduação considerando, naquele momento, questões da conjuntura com significativa incidência nas estruturas acadêmicas construídas pelos cursos de graduação, tais como: o avanço da precarização do ensino e do trabalho docente, a proliferação de cursos de graduação a distância, o debate sobre o exame de proficiência, a avaliação de desempenho do estudante e dos cursos pelo Inep, dentre outros. Colocou-se também a necessidade de um espaço para análise e definição, em âmbito nacional, de mecanismos de enfrentamento das questões identificadas nos resultados finais da pesquisa sobre a implementação das Diretrizes Curriculares, realizada pela Abepss em 2006 e concluída em 2008, fazendo-se a divulgação junto às unidades de ensino. Questões que, embora mais especificamente concernentes à graduação, são também de interesse da pós-graduação, quer como problemática que incide sobre de formação profissional e acadêmica, quer como temática e estudo e de pesquisa para contribuir com a graduação (ABEPSS, 2008b).

No tocante ao II Seminário Nacional de Pós-Graduação, a realização do evento partiu da necessidade de

[...] consolidação da articulação dos programas de pós-graduação de forma autônoma em relação às agências de fomento, mas com a clareza da importância da interlocução com as mesmas a partir de diretrizes político-pedagógicas e de linhas estratégicas de atuação acadêmica com a incorporação de necessidades do ensino de graduação em Serviço Social (ABEPSS, 2007).

Até 2005, a articulação dos programas dava-se fundamentalmente mediada pela Capes e pelo CNPq, contando com o empenho e compromisso das respectivas coordenações da área com os propósitos da entidade, cujas reuniões a Abepss é convidada. Assim, a proposta visou contribuir para ampliar a base de conhecimento sobre a política nacional de Pós-Graduação, com vistas a uma melhor qualificação das particularidades do Serviço Social junto às Agências de Fomento e Instituição de Ensino Superior (IES), no conjunto da área das Ciências Sociais Aplicadas, na perspectiva do avanço da construção de novos indicadores de qualidade nessa área. Igual- 
mente, houve também a expectativa de viabilizar efetivas articulações e profícuos intercâmbios entre os programas de Pós-Graduação em Serviço Social no Brasil e outros países da América Latina, orientando a construção de diretrizes político-pedagógicas e de pesquisa para a Pós-Graduação em Serviço Social (ABEPSS, 2008b).

Nessa direção, o evento ensejou a articulação de uma proposta preliminar de Grupos Temáticos de Pesquisa (GTP), na área de Serviço Social, no âmbito da Abepss, procurando avançar em um esforço desencadeado durante o X Encontro Nacional de Pesquisadores em Serviço Social (Enpess), realizado em Recife, em 2005, além de pautar-se na proposta, discutida e encaminhada ao CNPq, Capes e Finep para subáreas e especialidades na área de Serviço Social5. Foram organizados três grupos, de acordo com as seguintes subáreas: Fundamentos do Serviço Social; Questão Social e Trabalho; Política Social.

Esta orientação respaldou a estrutura do XI Enpess naquele ano, seguindo a experiência do $X$ Enpess (2006), e ao mesmo tempo constituiu-se num dos objetivos do evento: “[...] oferecer condições para a articulação entre pesquisadores fomentando a formação/consolidação de grupos e redes de pesquisa na área do Serviço Social na perspectiva do avanço do processo de formação de Grupos Temáticos de pesquisa (GTP) na área do Serviço Social” (ABEPSS, 2008c).

As discussões acumuladas constituíram a base que sustentou a proposta de inclusão dos Grupos Temáticos de Pesquisa (GTP) na estrutura da entidade viabilizada com sucesso na revisão dos estatutos naquele ano.

\footnotetext{
5 "O processo de revisão das áreas do conhecimento desencadeado pelos órgãos de fomento em 2005, embora não tenha sido concluído no âmbito dos mesmos, significou para o Serviço Social um momento de sistematização e demarcação de temáticas sobre as quais incidem a pesquisa e a produção intelectual que consubstanciam três subáreas: Fundamentos do Serviço Social; Trabalho e Questão Social; Política Social. Com esta delimitação no X Enpess (2006) e depois no XI Enpess (2008), a organização da apresentação de trabalhos foi orientada a partir dessas subáreas e como estratégia para a formação de Grupos Temáticos de Pesquisa (GT) no âmbito da Abepss" (ABREU; LOPES, 2008).
} 


\section{A REVISÃO DOS ESTATUTOS: O DESTAQUE PARA O ESTABELECI- MENTO DA SEDE FIXA EM BRASÍLIA (DF) E A CRIAÇÃO ÓRGÃOS DE APOIO}

A necessidade de adequação da estrutura da entidade às demandas do seu desenvolvimento e fortalecimento como associação acadêmico-científica reforçou e orientou o processo de revisão do estatuto, realizado em 2008, mediante o qual se destacam, como principais alterações, as ocorridas:

a) no Título I: Da natureza e finalidades, referente ao estabelecimento de uma sede fixa, com um corpo funcional técnico e administrativo próprio e de se reafirmar o foro jurídico da Abepss, em Brasília. Isto se fez necessário para garantir o enfrentamento das questões histórico-estruturais e conjunturais da entidade e os desafios acadêmicos e administrativos que se aprofundam no atual contexto - em particular, no referente à Revista Temporalis como instrumento importante para a Abepss como associação acadêmico-científica;

b) no Título III: Da Estrutura, Órgãos de Apoio e Competências, a inclusão na estrutura da entidade de órgãos de apoio acadêmico científico e órgãos de apoio técnico-administrativo, com funcionamento em sede fixa em Brasília, tendo em vista assegurar "condições físico-estruturais básicas necessárias ao exercício das funções acadêmico-científicas, políticas e administrativas da entidade, além de garantir a continuidade das atividades da entidade para além de cada gestão, particularmente as atividades relacionadas à Temporalis e à preservação da memória da entidade" (ABEPSS, 2007). A proposta apresentada e aprovada nesse processo consistiu em: i) Criação de três órgãos de apoio acadêmico-científico: Grupos Temáticos de Pesquisa; Comissão Editorial da Revista Temporalis; Comissões Temporárias de Trabalho; ii) Criação de órgãos de apoio técnico-administrativo: Secretaria Executiva da Abepss; Assessoria Jurídica; Assessoria Contábil; Assessoria de Comunicação (ABEPSS, 2008a). 


\section{A REESTRUTURAÇÃO DA REVISTA TEMPORALIS: A PERSPECTIVA DE INDEXAÇÃO E ENQUADRAMENTO NAS EXIGÊNCIAS DO QUA- LIS CAPES}

O avanço da pesquisa e produção intelectual na área do Serviço Social nas últimas décadas e as demandas quanto ao fortalecimento da Revista Temporalis como Revista Brasileira de Serviço Social um veículo importante da publicação científica e articulação acadêmica no país - colocaram a necessidade de avançar no processo de reestruturação dessa revista tendo presente, como já mencionado, a perspectiva de enquadramento nos padrões nacionais e internacionais de indexação bibliográfica e nas exigências do Qualis Capes assim como favorecer a sua expansão internacional.

Na perspectiva de indexação tendo como referência o Scientific Eletronic Library Online (SciElo), a gestão anterior (Abepss 2005-2006) buscou a assessoria técnica de Mércia Bernardes do conselho desse órgão. Entretanto, a revista, avaliada em B3 no sistema Qualis da Capes, defrontava-se com uma das grandes dificuldades que era a de manter-se atualizada, uma das primeiras e mais importantes exigências para a indexação. (ABEPSS, 2008d).

A gestão 2007-2008 fez um significativo esforço, mas não logrou superar essa dificuldade ao mesmo tempo avançando na complexidade das exigências dos órgãos indexadores e do sistema Qualis da Capes e em função, basicamente, da falta de condições objetivas, sobretudo, pela sobrecarga de atividades dos membros da diretoria que acumularam a função de comissão editorial. Isto levou tal equipe a propor, na mudança do estatuto, a criação de uma "comissão editorial", composta de membros para além da diretoria, como parte dos órgãos de apoio acadêmico-científico da Abepss, aprovada na forma do artigo 35 do novo estatuto.

Ainda na perspectiva de atualização da periodicidade dos números da Revista, foi proposta e iniciada a partir de 2007 a implementação do sistema de fluxo contínuo com chamadas através da página da Abepss, incluindo não somente o texto de divulgação da revista em português, mas projetando-se para a chamada também em inglês e em espanhol, considerando a exigência e a importância da internacionalização da revista (ABEPSS, 2008d). 
A partir do XI Enpess, iniciou-se um processo de vinculação deste evento ao fluxo contínuo de recebimento de artigos, considerando sua natureza científica, abrangência nacional e potencial mobilizador da comunidade científica do Serviço Social com vista à formação de um banco de artigos.

\section{ARTICULAÇÕES POLÍTICAS: POSICIONAMENTOS FRENTE A DESA- FIOS E POLÊMICAS}

Com a firme convicção de que a luta em defesa do projeto ético político-profissional é ampla e de que suas condições são construídas historicamente no movimento da sociedade, a diretoria da Abepss, no biênio 2007-2008, dá continuidade e amplia as articulações com entidades profissionais da área do Serviço Social, Conselho Federal de Serviço Social (CFESS), Conselhos Regionais de Serviço Social (Cress), Executiva Nacional de Estudantes de Serviço Social (Enesso), Centros Acadêmicos de Serviço Social (CA), além de outras entidades sindicais e movimentos sociais - como é o caso da Associação Nacional de Docentes do Ensino Superior (Andes), do Movimento dos Trabalhadores sem Terra (MST), da Coordenação Nacional de Lutas (Conlutas), dentre outros - a partir de um plano de lutas que privilegia as questões da formação e do exercício profissional. Todavia, reitera-se a ponderação de que

[...] os grandes desafios dos processos de luta no contexto atual da sociedade brasileira, considerando os avanços e a solidificação das políticas de flexibilização econômica, sob a ideologia neoliberal, cuja incidência sobre as condições objetivas das lutas e das organizações de mediação política da classe trabalhadora expressam-se, principalmente, na perda de significativas referências históricas, no campo econômico e político, com a reestruturação da produção e do trabalho, a partir da desarticulação dos grandes parques industriais, tipo ABC Paulista, berço das greves de 1978, da Central Única dos TrabaIhadores (CUT) e do Partido dos Trabalhadores (PT) na década de 1980, hoje fortes aliados no governo. Tem-se, assim, um contexto de expressivo retrocesso na organização da classe trabalhadora brasileira e na histórica solidariedade e luta dessa classe pela 
sua emancipação como classe e pela emancipação de toda a humanidade. Nesse movimento a classe trabaIhadora repõe-se como classe e reconstrói ou constrói suas instituições de mediação política (ABREU; LOPES, 2007).

Nesse contexto, as bases históricas da resistência e defesa do projeto ético-político profissional são tensionadas pelos desafios das organizações de mediação política da profissão, nos marcos históricos da organização e luta do conjunto dos trabalhadores. Desafios intensificados e aprofundados com a reconfiguração das condições concretas da prática profissional,

[...] centradas na assistência que como política no âmbito da seguridade é reforçada no enfrentamento das desigualdades, e constitui o principal espaço da prática dos assistentes sociais. Cresce entre esses profissionais, a partir da Lei Orgânica da Assistência - LOAS, e agora, do Sistema Único da Assistência Social - SUAS, a perspectiva da luta pela assistência como direito, cuja centralidade pode obstruir a perspectiva da luta fundamental na sociedade capitalista que é o direito o trabalho. Tem-se aqui o eixo problemático mais importante hoje para se confrontar o projeto ético-político alternativo do Serviço Social, pautado pela perspectiva de emancipação humana e a ação prática dos assistentes sociais no mercado de trabalho, cujas respostas impõem a articulação de forças sustentadas no conhecimento crítico sempre atualizado (ABREU; LOPES, 2007).

Nesse movimento contraditório, três eixos problemáticos polarizaram o debate na profissão no biênio 2007-2008 - como foi explicitado em outro artigo sobre o desempenho da Abepss nesse biênio (ABREU; LOPES, 2008) -, a saber: a precarização do ensino e do exercício profissional, com ênfase na proliferação do ensino de graduação a distância, a avaliação institucional da graduação e pós-graduação e o debate sobre o exame de proficiência. Questões polêmicas sobre as quais as discussões internas da Abepss aprofundaram e reafirmaram posicionamentos, explicitados, resumidamente, a seguir:

a) Em relação ao ensino de graduação a distância, o posicionamento contrário das entidades de Serviço Social, do qual a Abepss é 
protagonista, amplamente divulgado, considera que este tipo de ensino confronta-se radicalmente com os compromissos e princípios da formação profissional e colide com os fundamentos, competências e habilidades estabelecidos nas Diretrizes Curriculares para o curso de Serviço Social/1996. Reflete o acirramento e consolidação da política privatista, mercantilista, da Educação Superior assentada em baixo custo e elevada lucratividade. A diretoria da Abepss no biênio implementou ações específicas e em conjunto com a Enesso e o Cfess/Cress, em que se situam: a manifestação pública contrária aos processos de privatização e precarização da formação e à proliferação do ensino de graduação a distância; a luta pela abertura de novos cursos em 45 IES públicas, que não ofertavam cursos de Serviço Social, e a ampliação de turnos e números de vagas em instituições com cursos já existentes;

b) Em relação aos processos de avaliação institucional implementados pelo Inep (graduação) e à avaliação desenvolvida pela Capes sobre a pós-graduação, considerando a grande distância das condições institucionais entre as duas modalidades de avaliação nessas instâncias da formação, observa-se que a pós-graduação com estrutura e metodologia rigorosas pautadas em padrões de excelência e a graduação marcada pela precarização e rebaixamento da qualidade aproximam-se pelo caráter obrigatório e pela lógica produtivista, quantitativista, que, por sua vez, presidem os processos avaliativos. Além disso, particularmente em relação à avaliação dos cursos de graduação, a ênfase no Exame Nacional de Desempenho dos Estudantes (Enade) - um dos componentes do Sistema Nacional de Avaliação do Ensino Superior (Sinaes), que envolve também a avaliação interna e externa dos cursos - tende a resultados imediatos, direcionados para o estabelecimento de um ranking de cursos e instituições, contrariando uma concepção de avaliação acadêmica, defendida por esta entidade, ou seja, uma avaliação voltada para a identificação e superação de dificuldades e obstáculos com que se defronta a educação no Brasil. A diretoria da Abepss manteve um posicionamento de respeito à autonomia dos estudantes quanto ao boicote ao Enade e o reconheceu publicamente como uma estratégia de resistência à (contra) reforma da Edu- 
cação Superior, que repercute fortemente nos resultados desse exame, comprometendo-os como indicação da implementação das Diretrizes curriculares da entidade (ABEPSS, 2005);

c) Em relação ao debate sobre o exame de proficiência desencadeado naquele contexto, as entidades do Serviço Social manifestaram-se em divergência a este exame e os argumentos convergiam. A diretoria da Abepss respaldava-se na noção de que essa proposta não traz melhoria na formação, mas tende, ao contrário, a encobrir o real problema a ser enfrentado, qual seja, o rebaixamento da qualidade de ensino nos cursos de graduação, tanto a distância quanto presenciais - o que também não constitui uma alternativa para filtrar o ingresso no mercado como argumentam os que defendiam este exame. Além disso, a avaliação individual pós-curso, como é igualmente o caso do Enade, ao invés de levar os cursos a se qualificarem, favorecem e acirram a competitividade e a livre concorrência e, de outra parte, estimulam a proliferação de cursinhos preparatórios para o exame, contribuindo para responsabilizar individualmente os sujeitos e penalizá-los pela ausência de qualidade de ensino e omissão do Estado.

\section{CONSIDERAÇÕES FINAIS}

Ressalta-se que o desempenho da Abepss nesse biênio pautou-se na importância do avanço do debate democrático e da criação de condições para o enfrentamento das questões acadêmicas e profissionais do Serviço Social no quadro das transformações da sociedade brasileira promovidas pelas saídas capitalistas sob a orientação neoliberal à própria crise do capital. Tais saídas incidem mais perversamente sobre o trabalho e a classe trabalhadora e agravam profundamente a questão social - base histórica do campo interventivo em que se insere o Serviço Social -, cujas demandas imediatas aos assistentes sociais apontam redimensionamentos profissionais com expressões no exercício profissional, na formação acadêmica, na produção do conhecimento e na organização política.

Espera-se que os elementos apontados neste texto possam contri- 
buir com o esforço de recuperação da memória da Abepss em sua trajetória a partir de 1998, iniciativa de grande importância para a própria historia da entidade e do Serviço Social brasileiro. Daí a relevância da edição desse número especial da Temporalis, para a memória da entidade, para o seu fortalecimento e reafirmação dos seus propósitos na direção estratégica do projeto ético-político profissional.

Parabéns a Abepss pelos 65 anos de profícuos trabalhos ao Serviço Social brasileiro, parabéns a sua atual diretoria pela oportuna e relevante iniciativa.

\section{REFERÊNCIAS}

ABEPSS. Plano de Atividades Abepss 2007-2008. São Luís: Abepss, 2007.

- Boletim Especial sobre os resultados do Enade. Recife: Abepss, 2005.

. Estatuto da Associação Brasileira de Ensino e Pesquisa em Serviço Social - ABEPSS. São Luís: Abepss, 2008a.

. Il Seminário Nacional de Pós-Graduação e a Oficina Nacional de Graduação. São Luís: Abepss, 2008b.

. XI Encontro Nacional de Pesquisadores em Serviço Social - XI Enpess. São Luis: Abepss, 2008c. 2008d.

. Informe Temporalis - gestão 2007-2008. São Luís: Abepss, ABREU, M. M.; LOPES, J. B. Formação profissional e diretrizes curriculares. Revista Inscrita, Brasília, n. 10, 2007.

. Abepss: a perspectiva da unidade da graduação, pós-graduação e produção do conhecimento na formação profissional. Revista Serviço Social e Sociedade, São Paulo, v. 95, p. 173-188, 2008.

ANTUNES, R. Os sentidos do trabalho: ensaio sobre a afirmação e a negação do trabalho. São Paulo: Boitempo, 1999. 